\title{
Using the investment projects management in developing residential in Baghdad
}

\author{
$H$ M A Asfoor ${ }^{1,2, *}, A$ A T AL-Jandeel ${ }^{3,4}, K K$ Igorevich $^{5}$ and $L A$ Ivanovna $^{6}$ \\ ${ }^{1}$ Postgraduate Student, Department of Automobile Transport, Faculty of Motor Transport, South Ural State \\ University, Lenin Avenue, 76, Chelyabinsk, 454080, Russian Federation. \\ ${ }^{2}$ Deputy Chief Engineer gDiwaniya Investment Commission (DIC), Diwaniya, Iraq. \\ ${ }^{3} \mathrm{M}$.Sc student of the Department of Price Formation in Construction and Industry, Ural federal University named \\ after the first president of Russia B.N.Yeltsin, Miraulitsa, 17, Yekateringburg, 620002, Russian Federation. \\ ${ }^{4}$ Ministry of communication (MOC), Baghdad, Iraq. \\ ${ }^{5} \mathrm{Head}$ of the Department of Price Formation in Construction and Industry, Ural federal University named after the \\ first president of Russia B.N.Yeltsin Miraulitsa, 17, Yekateringburg, 620002, Russian Federation. \\ ${ }^{6} \mathrm{M}$.Sc student of the Department of Price Formation in Construction and Industry, Ural federal University named \\ after the first president of Russia B.N.Yeltsin Miraulitsa, 17, Yekateringburg, 620002, Russian Federation. \\ Email: iraqieng2003@yahoo.com*, anas_star2001@yahoo.com
}

${ }^{*}$ Corresponding author.

\begin{abstract}
There are many heritage residential neighborhoods in Baghdad some of them belong more than thousand years because this city is taken the important cultural and social place for hundreds years. In last decades, the issue of preserving, rehabilitating and investing heritage residential neighborhoods has received increasing attention at all political, cultural and academic studies.

The biggest problem that prevent the developing design in these places are the historical privacy, the weakness in the structures, the high cost because the rehabilitation and maintenance require the high and special skills experiences. Because of the historical and cultural value and what it represents a wealth of all humanity, the studies and researches that studied these subjects avoided the wading in make bold decisions to get the new design of these places , but limited their interest to the study of job investment in those neighborhoods in particular. In addition to, the role of maintenance and rehabilitation operations in supporting this investment, and from the reality of the shortcomings in the study of economic investment policies in dealing with these neighborhoods and the mechanism of protecting them. The importance comes of studying the maintenance and investment policies of these neighborhoods.
\end{abstract}

Keywords: Heritage Residential Neighborhoods, Investment, Project Management, rehabilitation, maintenance and investment returns.

\section{Introduction}

The heritage residential neighborhoods one of the important city's landmarks and the tourist attractions, the investment in this place will be returned the huge investment profits and that will develop the city or town where located these places [1]. Recently, the international community has paid great attention to strengthening the interdependence between cultural heritage and its environment, recognizing the strategic role of cultural heritage for sustainable development. Cultural heritage, as a key to sustainable development [2]. One of the heritage residential neighborhoods that was not developed up to now in Baghdad, the capital of Iraq, is the Al-Bataween neighborhood that was chosen as a case study in this article because it consider on of the ancient places in Baghdad, back to the Abbasid era $750 \mathrm{AD}$, [3]. In the subsequent eras from the Ottoman era, in 17th and 18th century as this region suffered from wars and neglect over the ages and it needs the full rehabilitation and the investment one of the best solution due to its ancient historical extent, [4].

The Al-Bataween neighborhood is located on the eastern side of the capital, Baghdad, surrounded by the main and commercial streets, [5]; as shown in (Fig. 1). The Al-Bataween neighborhood is distinguished by its ancient architectural style of Al-Shanasheel Al-Baghdadi and the beautiful old decorations. It is considered one of the important and strategic areas in terms of its geographical and historical location, which made it the focus of the attention of many local and foreign tourists. 


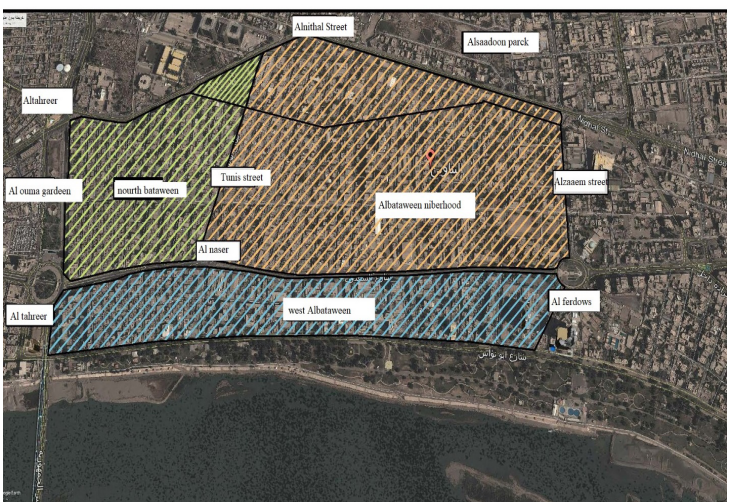

Fig. 1. The location of Al-Bataween neighborhoods, Iraq, [6].

\section{Investing in Important Archaeological Sites}

The policy of investing important archaeological areas and how to benefit from the rehabilitation of archaeological areas, as the main objectives of investing and rehabilitating archaeological areas are:

Invest these neighborhoods economically and housing land.

Operate them as recovery centers for the surrounding neighborhoods.

-The economic investment and the use of legislation and implementation a major role in solving the problem of deterioration and deterioration suffered by those neighborhoods.

-The method of partnership between the public and private sectors plays a role in investing heritage residential neighborhoods locally.

To rehabilitate the heritage residential areas and invest them properly, the following things must be achieved [5]:

Securing local and international legal guarantees that protect this heritage, and guarantee all its rights in maintenance, rehabilitation and investment. In addition to the recognition of international conventions, Retaining and supporting this heritage to see the potential of these instruments on the qualification level and investment both that, and to identify the various conservation methods in order to choose the appropriate region method and to identify the sustainable preservation and derived from the social, economic and functional potential. Finally, a mechanism that ensures labor consultant as a way of re-sustainable heritage preservation processes to obtain the largest number of investment opportunities.

Managing, financing and implementing conservation consultancy work and creating investment opportunities by liberating the value of the land and obtaining the necessary funding to invest in heritage areas through coordination between all relevant parties, and proposing an appropriate methodology for managing the heritage advisory work.

Optimization algorithm for multi-criteria evaluation of projects on archaeological sites. Operational research is the discipline that studies, on a quantitative basis, conceptual models. From decision-making processes related to the functioning of organized systems, and forecasting methods behavior of these systems and making choices that improve their performance as well tools for evaluating the outcome of some judgments a priori [2, 7]. In particular, the decision support tools are useful when they are required to manage limited resources to maximize (or reduce) objective function. Thus, many selection processes can be treated as traceable improvement models for a mathematical programming model, Equation (1):

$$
\left\{\begin{array}{l}
\max (0 \min ) c\left(x_{1}, \ldots, x_{n}\right) \\
\varphi_{m}\left(x_{1}, \ldots, x_{n}\right) \leq b_{m} \\
x \in X
\end{array}\right.
$$

Where $C(x)$ is the objective function, $\left(\Phi_{m}\right)$ the system of constraints to be taken into account in the calculation of the optimal value, and $(X)$ the set of variables of the problem [5]. Resolution problem then expressed in formal language expressing the two-way correspondence between relationships in the real world and mathematical expressions

Mathematical programming problems can be categorized in one of two ways:

- Linear programming problems, if the objective function and the functions defining the constraints are linear;

- Nonlinear programming problems, if at least one of the functions defining the problem is not linear.

The linear hypothesis finds widespread practical feedback [9]. In fact, many real cases can be expressed with a sufficient approximation precisely in the terms suggested by the linear Programming. In particular, this occurs in connection with the problems of choice between urban areas. Redevelopment projects or to improve sites with specific functions, even if they are important.

Historical and architectural values [10]. In contrast, linear programming problems can be of continuous improvement, with values in $\mathrm{Rn}$; from full (or discrete) optimization, when the values are in $\mathrm{Zn}$; Mixed, with both full and continuous values.

In all cases, choosing the best algorithm for solving the problem in question is fundamental. In fact, the algorithm is efficiently related in terms of the resources needed to determine Solve the problem. 
These resources relate to occupied memory and computation times, i.e., Algorithm execution times. In the context of all linear programming, the main solution algorithms are as follows:

dynamic programming algorithms, based on the Bellman optimization principle; Implicit enumeration algorithms, such as Sub and Bound (B\&B) algorithms, which are based on the recursive division of the solution space; And cutlevel algorithms, such as Gomori algorithms [11].

With a view to pursuing the multiple objectives of preserving and enhancing archaeological sites $(m$, with $m>1$ ), which impose a multi-criteria assessment approach, consider the problem of choosing between projects, not all of which are achievable due to budget constraints. Linear programming tools can summarize this problem. In fact, both objective function and constraint relations can be expressed in linear form. Specifically, since the individual project cannot be segmented, algorithms suitable for Discrete Linear Programming (DLP) can be implemented [12].

Among the accuracy, algorithms made available by operational search to choose from among $n$ projects, we use one $\mathrm{B} \& \mathrm{~B}$. This algorithm is widely applied to solve selection problems using multi-criteria logic, allowing the expectation of the complexity of the problem to be addressed while reducing the resulting computation time, with respect to Dynamic programming algorithms and cutting levels algorithms. The bed and breakfast is based on a procedure that leads from solving a "difficult" problem to solving two or more simple sub-problems. Starting with the construction of the accepted solution tree (the branch process), the solution of the original problem is returned to the solution of the sub-problems identified in the smaller and simpler areas to be solved. Subproblems that do not have an optimal solution (constrained process) are ignored.

\section{Sources of financing the investment of archaeological sites}

In the beginning, it is important things you must know the sources of financing investment areas and the most important archaeological sources:

State Mtthelh Central Bank.

1. Some service ministries that are directly related to the work of investment projects in heritage areas.

2. Credit / National Fund for places and sites of historical significance fund.

\section{The impact of the economy on investment in heritage areas}

Profit is one of the factors affecting the investor's decisions regarding determining the type and size of the investment, and the profit motive makes the investor hedging against the risks facing his investment, as it may hinder his decision to invest in any economic activity. By preferring to invest his money in the activities of keeping his money without investing a guaranteed profit, instead of being exposed to fluctuation and devaluation and its purchasing power, whether it is private or public. However, the investor is either exposed to a set of obstacles that must be overcome and turned into incentives for investors; these restrictions relate to [7];

- Inflation, price and monetary policy.

- Taxes and Fees.

- Political stability, security and economic.

- Laws and regulations related to investment.

First: Inflation, price and monetary policy: -

The impact of inflation and price and monetary policy is evident on those with limited incomes, as prices of goods and services are exposed from time to time to fluctuations on a continuous basis. Most of these fluctuations are compatible in movement and direction, and the percentage of change in them may vary, but most of them share the same direction, and this case applies what is produced to different groups of goods (such as prices of building materials, wages of workers, machinery and equipment...etc), [14].

The citizen participates fully in the rehabilitation of the facades of houses for the heritage and commercial areas in the heritage area. For example, loan assets and interest, real estate instalments and land licenses.

Insurance workers' wages and salaries and other contractual obligations that are deferred or take a certain period of time to be implemented, during which the debtor is obligated to pay a certain amount of money as recorded in the contract, without an increase or decrease in the value of money at the time of fulfilment having any effect. It is clear that any change in the value of money must change the economic position of the contracting parties, and it appears that the longer the commitment period, the wider the range of fluctuations in the value of money, due to the constant change in the prices of goods and services. In the case of inflation (a rise in the price level and a decrease in the value of money), the economic condition of debtors improves and creditors are harmed, and, conversely, in the case of deflation (a rise in the value of money and a decrease in the 
price of goods), debtors are harmed and creditors benefit. . From an economic point of view, an important point should be noted is long-term loans, since the creditor is harmed by the depreciation of money at the end of the loan term. The condition of those affected by inflation (the depreciation of money) includes creditors (bondholders, bank deposit holders, policyholders, provident funds) [8], as well as those with fixed incomes and premium wages and salaries their exposure to slow change, pensions, social benefits...etc.

Inflation also affects the operation of economic resources and the level of national product, as rising prices are usually accompanied by an increase in the volume of employment (investment). The rise in the prices of produced goods leads to an increase in the profits made, and thus brings about extraordinary changes in the economic structure and areas of investment, as investors prefer to invest their money in businesses that bring them significant profits. Periods of continuous price hikes are also characterized by the tendency of funds to speculate in the purchase of land and real estate or investment in residential or heritage areas, as they require full economic determination because they target archaeological tourism inside and outside Iraq, as well as avoiding it. Industries intended for domestic consumption that are not subject to state control. Investment also tends to produce luxury goods that are consumed by the rich classes, business owners and other classes whose income increases due to inflation.

\section{Taxes and Fees}

Taxes and fees are among the factors affecting the type and size of investment, as they constitute an attraction or expulsion factor for local and foreign investments through the laws and legislations in force in any country, [13]. Therefore, states grant full tax exemptions for a certain period or partial exemptions for a specified number of years. As well as exemption from customs duties granted to imported materials for the establishment and processing of investment projects. It is determined by laws to attract investments and encourage investors by reducing the costs of establishing and operating projects, as well as Investment Law No. 13 of 2006 and its amendments.

\section{Conclusion}

Population pressure on housing in traditional areas due to rapid urban growth. The apparent inability of the traditional urban fabric to adapt to the requirements of modern life. The urban fabric of the traditional city, with its cohesive pattern of courtyard housing units occupying the total area of land on which they are built, has faced urbanization and growth: increasing urban population, expanding land, expanding land. The problems of the historical centers in the city of Baghdad, which led to the process of change, which was linked to four axes. Problems and problems of urban design, urban planning and urban management. Urban design problems, the most important of which is the process of building streets, which takes place without a comprehensive study and without preparing a comprehensive and integrated urban design. Where passes through the streets of historical centers. It causes the isolation of the old fabric and the historical and heritage buildings that compose it. Where the penetrating street allows traffic (vehicles) to cross, is delimited by two rows of high-rise buildings, represents the largest open space within the historic center, and constitutes. This is the isolation and disconnection in the urban fabric of the historical area in terms of (shape, shape, scale, and connection with the axes of the historical movement) as in Al-Khalafa Street / AlRusafa Historical Center.

A follower of the operational steps of planning such centers will note that as soon as the main roads surrounding an area are opened, the process of building buildings on either side of these roads begins. The ground floors have been converted into shops, and the need for someone to service these shops appears, such as the car parks. With the passage of time, the need increases and the problem worsens, then another stage of incision and expansion of these streets begins, and buildings on the main streets and facades become hidden behind their degraded areas. Urban planning problems, basic design and comprehensive development design (for the city of Baghdad) and its planning requirements and planning studies with historical centers such as the construction of intersections that conflict with Sometimes with the introduction of vehicular traffic, roads, bridges, and a classification (main distribution street) within these two dates centers.

In addition, AL-Rusafa for example with the flow of traffic that penetrated and crossed the historical center:

Urban management problems:

These include the following:

1. Linear Mechanisms weak urban management mechanisms and requirements for historical centers.

2. Entities: multiple public bodies related to heritage and historical buildings. 
3. More information about this source text Source text required for additional translation information:

4. Financing: problems of financing projects related to historical centers. Building Reuse Use: Misuse and Heritage.

The study (Sector Strengthening Project to Existing Urban Governance Policies) indicated that many governments in developed, developing countries have adopted multiple, and wide-ranging policies to meet the requirements of their citizens, especially in historically poor areas with regard to shelter and basic urbanization. The role of the government should include:

1. Developing legal tools that support the rights of residents of historical areas to obtain shelter commensurate with their capabilities.

2. Financial support for urban residents by creating effective support mechanisms for them. Encouraging the private sector to provide alternatives and within the financial capabilities of the residents of historical areas

3. Revitalizing the housing market and strengthening financial institutions to work effectively in it, because residential use constitutes a large proportion of land use in historical centers

One of the most important factors of competition in investment projects is the time factor and speed of completion. When the company specializes in the field of investment in the tourism and archaeological fields and has a lot of business in this field. It is easy for the company to know the time of completion of the project or to speed up the completion of the work and deliver it on time with modern machines and technology, thanks to the development in the world of technology.

\section{References}

1. Kharofa, O. H. Urban Renewal Policies According to Sustainability Methods (Evaluating Of Traditional Cities, Mosul City as a Sample). Al-Qadisiyah Journal for Engineering Sciences, 7(3), 105-133, (2014).

2. UNESCO. The Hangzhou Declaration. Placing Culture at the Heart of Sustainable Development Policies. Adopted in Hangzhou, People's Republic of China, on 17 May 2013. http://www.unesco.org/new/fileadmin/MULTI MEDIA/HQ/CLT/images/FinalHangzhouDecla ration20130517.

3. Altaee, Z. M. J., \& Al-Ani, M. J. Urban renewal as a tool of cities sustainability Sulaimani as a case study-north
Iraq. Periodicals of Engineering and Natural Sciences (PEN), 8(2), 971-990, (2020).

4. Korte, B.; Fonlupt, J.; Vygen, J. Optimisation Combinatoire: Theorie et al. Gorithms, 1st ed.; Springer: Paris, France, 2010; ISBN 978-2287-99036-6.

5. Municipality of Mayoralty of Baghdad, Iraq.

6. https://www.google.com/maps/@37.0625,95.677068,2z.

7. Amos, Perl mutter, "Islamic Fundamentalist, Network",Washington Times, January(22) , 1993.

8. Daniel Pipes, Muslims are Coming, "Muslims are Coming", National Review, November (19), 1990.

9. De Mare, G.; Manganelli, B.; Nesticò, A. Dynamic Analysis of the Property Market in the City of Avellino (Italy), 1st ed.; Springer: Berlin, Heidelberg, 2013; pp. 509-523.

10. Nesticò, A.; Morano, P.; Sica, F. A model to support the public administration decisions for the investments selection on historic buildings. J. Cult. Herit. 2018, 33, 201-207.

11. Vercellis, C. Ottimizzazione. Teoria, Metodi e Applicazioni, 1st ed.; the McGraw-Hill Companies: Milano, Italy, 2008; ISBN 9788838664427.

12. Thuesen, G.J.; Fabrycky, W.J. Economia per Ingegneri, 1st ed.; IL Mulino-Prentice Hall: Bologna, Italy, 1994; ISBN 8815034277.

13. Alqatrani, F. S. A. The Historical Dimension and Physical Characteristics of Al-Shanasheel Heritage Buildings in the Old City of Basra (Iraq). Journal of Basra researches for Human Sciences, 45(2), (2020).

14. Alamiri, S. A., \& Alzubaidy, D. M. The Impact of Western Culture on the Transformation of Residential Patterns in One of the Heritage Areas in Baghdad (Neighborhood CREMAT/Salhiya-Baghdad Model). The Academic Research Community publication, 2(1), 6, (2018). 